\title{
Relationship of Sodium Chloride Tolerance and Serological Group of Staphylococcal Phages
}

\author{
By B. WEST* AND FLORENE C. KELLY \\ Department of Microbiology, University of Oklahoma Medical Center, \\ Oklahoma City, Oklahoma, U.S.A.
}

(Received 4 September 1961)

\begin{abstract}
SUMMARY
Twenty-two staphylococcal bacteriophages representing serological groups A, B, F and L were examined for activity after incubation of free phage in $10 \%(\mathrm{w} / \mathrm{v}) \mathrm{NaCl}$ Trypticase soy broth for $24 \mathrm{hr}$. at $30^{\circ}$. The mean decrease in plaque-forming units for ten phages of serological group $\mathbf{A}$ was $13 \%$; in no instance was inactivation of any group A phage greater than $33 \%$. All but one of nine group B phages were $88 \%$ or more inactive after incubation in the $10 \% \mathrm{NaCl}$ broth; the single exception was phage 83 with slightly more than $40 \%$ inactivation in both $0.5 \%$ or $10 \% \mathrm{NaCl}$ broth. Serological group $\mathbf{F}$ phage $42 \mathrm{D}$ resembled phages of group $\mathrm{A}$, whereas phage 77 of group $\mathrm{F}$ and group $\mathrm{L}$ phage 187 were intermediate between group $\mathrm{A}$ and $\mathrm{B}$ phages with respect to $\mathrm{NaCl}$ stability.
\end{abstract}

\section{INTRODUCTION}

The effect of the ionic environment on bacteriophages has been the subject of many investigations. Relatively few of the studies reported, however, have been concerned with the stability of free phages in the presence of high concentrations of salt. Bronfenbrenner (1925) observed that concentrations of $\mathrm{NaCl}$ greater than $1 \%$ inactivated $99 \%$ of phage, although the particular phage tested and time required for inactivation were not specified in his report. Adams (1949) examined the inactivating effects of temperature on coli phages, particularly $\mathbf{T} 5$, in concentrations of $\mathrm{NaCl}$ ranging from $0 \cdot 01$ to $2 \mathrm{~N}$. He found that inactivation of phage $\mathrm{T} 5$ was almost complete after $1 \mathrm{hr}$. at $37^{\circ}$ in solutions containing less than $0 \cdot 2 \mathrm{~N}-\mathrm{NaCl}$, whereas at concentrations of $0.4 \mathrm{~N}$ and $0.8 \mathrm{~N}$ there was no significant decrease in plaque count. Increase in sodium ion concentration resulted in increased stability of phages to the inactivating effects of temperature (about $50^{\circ}$ to $70^{\circ}$ ); phage $\mathrm{T} 5$ was equally stable in $2 \mathrm{~N}-\mathrm{NaCl}$ solution and in nutrient broth. In studies on the effect of electrolytes on the adsorption of staphylococcal phages, Rountree (1951) noted that, in the free state, some phages were partially inactivated by $1 \%$ sodium citrate. Experiments to determine the quantity and kind of electrolytes giving maximum adsorption included $20 \mathrm{~min}$. incubation of free phages, as well as phage + bacteria mixtures, in aqueous solutions which contained a high percentage of $\mathrm{NaCl}$. Some staphylococcal phages were unstable in such simple salt solutions although adsorption occurred in certain instances.

* Present address: Communicable Disease Center, United States Public Health Service, Atlanta 22, Georgia. 
The present work was begun when it was observed that staphylococcal phage 81 lysed its propagating staphylococus on agar medium containing concentrations of $\mathrm{NaCl}$ up to $10 \%$, whereas sore other staphylococcal phages were inactive at $\mathrm{NaCl}$ concentrations greater than $3 \%$.

\section{ME'IHOIS}

Phages and staphylococci. Phages were selected on the basis of preliminary observations and as examples of each of the staphylococcal typing groups. Arranged according to serological group the phages used were as followss

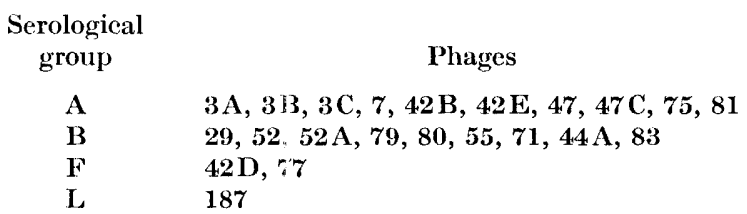

Staphylococci used were the phage propagating strains originally obtained, together with the phages, through the courtesy of Dr J. E. Blair.

Preparation of phage suspensions. Corresponding dilutions of each phage, designed to contain from 100 to 300 plaque-forming units $/ 0 \cdot 1 \mathrm{ml}$., were made in $10 \mathrm{ml}$. amounts of (1) commercially prepared (Baltimore Biological Laboratories; BBL) Trypticase soy broth of $0.5 \%(\mathrm{w} / \mathrm{v}) \mathrm{NaCl}$ and (2) the same broth to which suflicient $\mathrm{NaCl}$ was added to make a final concentration of $10 \%(\mathrm{w} / \mathrm{v})$. At $10 \% \mathrm{NaCl}$ concentration the $\mathrm{pH}$ value of the broth was decreased from $7 \cdot 2$ to $6 \cdot 8$. No adjustment of $\mathrm{pH}$ value was nade since, in previous experiments, variation of $\mathrm{pH}$ value within this range had no effect on the lytic activity of ten representative phages tested in media containin $0.5,3,7 \cdot 5$ and $10 \%(\mathrm{w} / \mathrm{v}) \mathrm{NaCl}$.

Plaque counts. Within 5-10 min. after dilution samples $(0.3 \mathrm{ml}$. $)$ of each phage broth were withdrawn and dispensed in $0.1 \mathrm{ml}$. amounts to each of three $13 \times$ $100 \mathrm{~mm}$. tubes which contained $0.1 \mathrm{ml}$. of a 6 -hr., $37^{\circ}$, Trypticase soy broth culture of the appropriate staphylococcus. Immediately thereafter $3 \mathrm{ml}$. melted cooled soft nutrient agar (Trypticase soy broth $+0.6 \%$, w/v, agar) was added to each tube; the contents were mixed and layered over the surface of regular Trypticase soy agar (BBL) in a standard P(tri plate. When the soft agar layer was firm, the plates were inverted and incubated at $30^{\circ}$. All plaque counts except those of phages 71 and 79 were made after 24 hr. incubation. Plaques of phages 71 and 79 were counted after $18 \mathrm{hr}$. because futher incubation resulted in overgrowth by the staphylococci. After withdrawal of the initial (0) sample, each phage-broth was incubated at $30^{\circ}$. At the end of 24 hr. incubation, plaque counts of both the $0.5 \%$ and $10 \% \mathrm{NaCl}$ broth suspensions were made according to the method used for determining the initial counts. [n a series of similar experiments plaque counts were made at intervals throughout the $24 \mathrm{hr}$. period.

\section{RESULTS}

The results of plaque counts before and after $24 \mathrm{hr}$. incubation at $30^{\circ}$ in $0.5 \%$ and $10 \% \mathrm{NaCl}$ broth indicated that phages of serological group $\mathrm{A}$ were more stable in the presence of $10 \% \mathrm{NaCl}$ then were the group B phages. Of the ten group $\mathrm{A}$ 
phages studied only phage $47 \mathrm{C}$ showed as much as $33 \%$ decrease in plaque-forming units, whereas the others of this group retained $72 \%$ or more of their activity after exposure to the higher concentration of $\mathrm{NaCl}$ (Fig. 1). The mean survival of the ten group A phages, after $24 \mathrm{hr}$. in $10 \% \mathrm{NaCl}$ broth, was $87 \%$. Conversely, eight of the nine group B phages tested showed $88 \%$ or more inactivation under the same conditions (Fig. 2). The one exception, phage 83, though less sensitive to

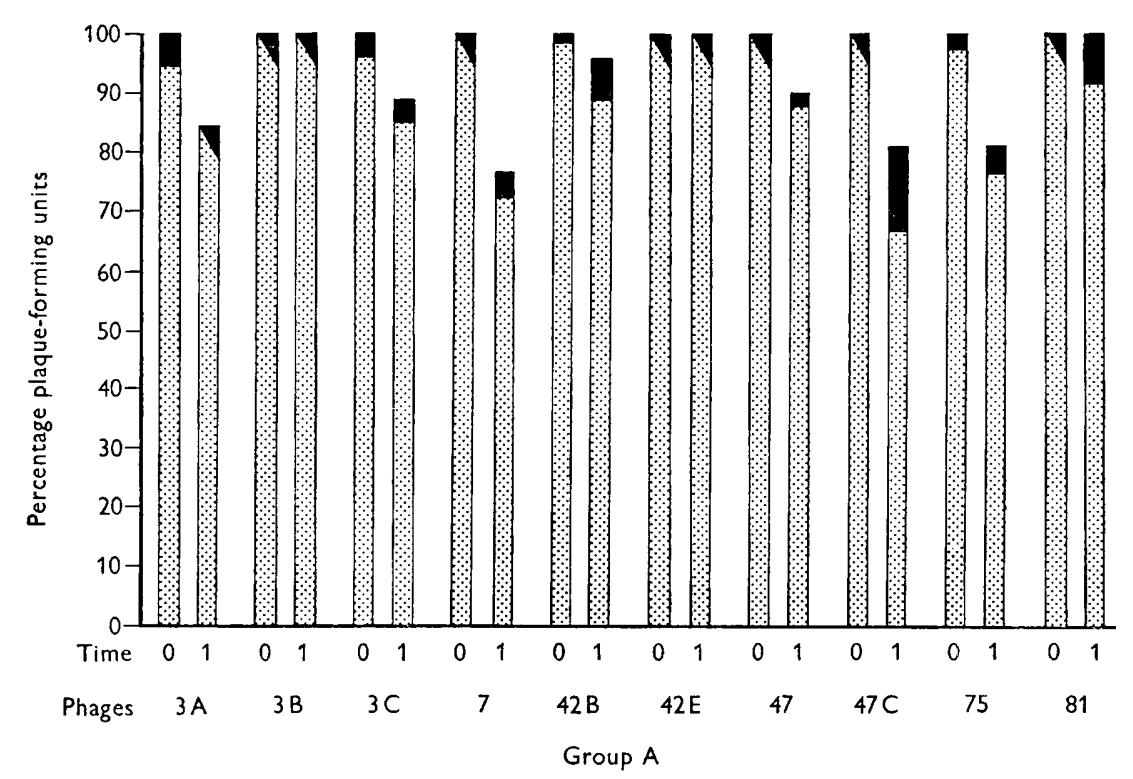

Fig. 1. Activity of serological group A staphylococcal phages after incubation of free phage in $0.5 \% \mathrm{NaCl}$ or $10 \% \mathrm{NaCl}$ in Trypticase soy broth at $30^{\circ}$. Percentages based on plaque counts of initial phage suspension (0) and after $24 \mathrm{hr}$. (1).

$\mathrm{NaCl}$ broth; $\mathrm{Fr}, 10 \% \mathrm{NaCl}$ broth.

$\mathrm{NaCl}$ than the rest of the group $\mathrm{B}$ phages, was inactivated to about the same degree in $0.5 \% \mathrm{NaCl}$ broth as in $10 \% \mathrm{NaCl}$ broth, 41 and $44 \%$ decrease, respectively. (Results with phage 83 do not appear in Fig. 2 because its serological group became known to us, through personal communication from Miss Miriam Carr, after completion of the figure.) The $\mathrm{NaCl}$ sensitivity of the group $\mathrm{B}$ phages was also shown by a decrease in the number of plaque-forming units within 5-10 min. after initial contact of most of these phages with $10 \% \mathrm{NaCl}$ broth. Such an immediate effect was not produced by exposure of group A phages to the same $10 \% \mathrm{NaCl}$ broth. Results with group $\mathrm{F}$ phages (42 D and 77) and group L phage 187 indicated that they were more $\mathrm{NaCl}$ tolerant than the group $\mathrm{B}$ phages, but only phage $42 \mathrm{D}$ resembled a typical group A phage in this respect (Fig. 2).

Comparison of the mean percentage decrease in plaque counts after holding the group $\mathrm{A}$ and group $\mathrm{B}$ phages in $\mathbf{0 . 5} \% \mathrm{NaCl}$ broth and in $10 \% \mathrm{NaCl}$ broth for $24 \mathrm{hr}$. is presented in Table 1 ; the extremes in variation of the stability of individual phages within each group are also shown. It will be noted that survival of active group $\mathrm{A}$ phages in $0.5 \% \mathrm{NaCl}$ broth and in $10 \% \mathrm{NaCl}$ broth are remarkably similar. Most of the group B phages, as well as those of group A, appeared to be 
quite stable in $0.5 \% \mathrm{NaCl}$ broth, although plaque count decrease in the case of phage 55 after $24 \mathrm{hr}$. incubation in $0.5 \% \mathrm{NaCl}$ broth was $59 \%$, as compared to $\mathbf{8 8} \%$ in $10 \% \mathrm{NaCl}$ broth. The instability of phage $\mathbf{5 5}$ in ordinary Trypticase soy broth was exceeded only by that of group L phage 187, which proved to be $67 \%$ inactive after $24 \mathrm{hr}$. in $0.5 \% \mathrm{NaCl}$ broth and $\mathbf{7 2} \%$ inactive after the same time in $10 \% \mathrm{NaCl}$ broth.

In other experiments, plaque counts of samples taken at intervals throughout the incubation period revealed that, when the activity of a phage was decreased after

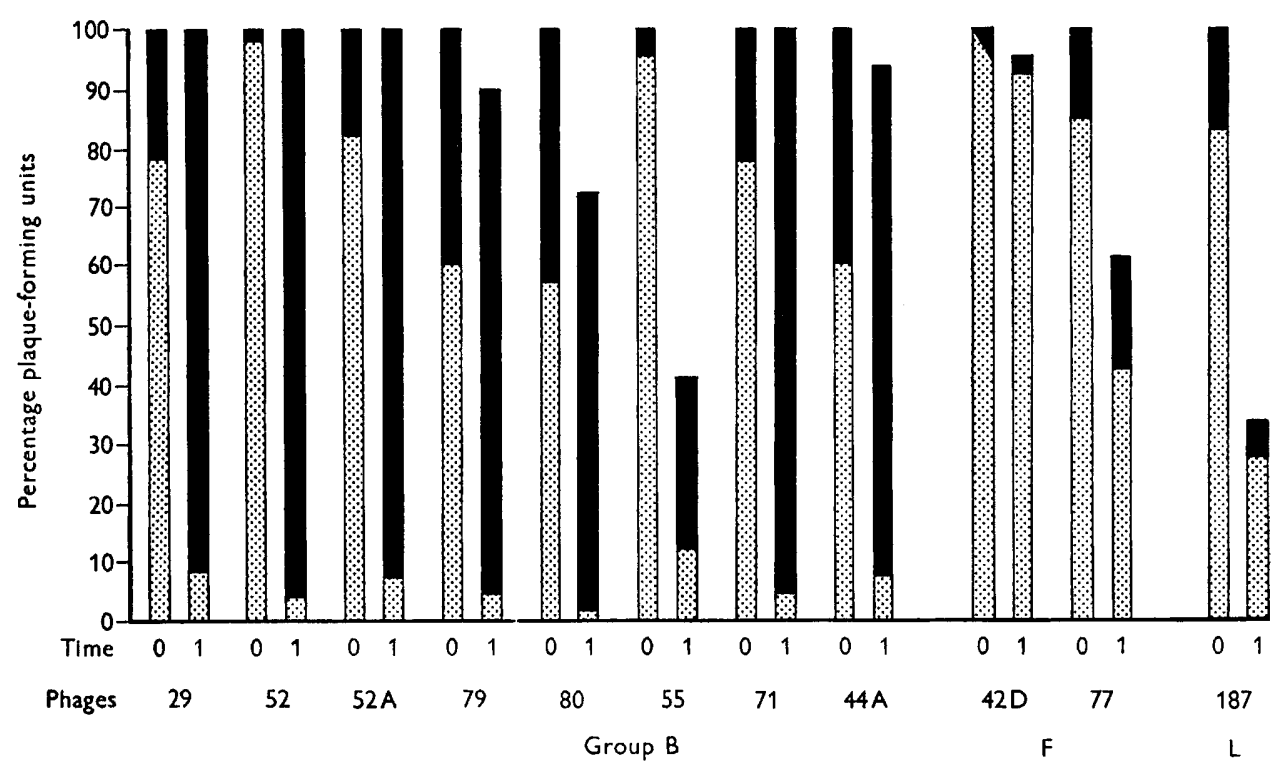

Fig. 2. Activity of serological group B, F and $\mathbf{L}$ staphylococcal phages after incubation of free phage in $0.5 \% \mathrm{NaCl}$ or $10 \% \mathrm{NaCl}$ in Trypticase soy broth at $30^{\circ}$. Percentages based on plaque counts of initial phage suspension (0) and after $24 \mathrm{hr}$. (1).

$0.5 \mathrm{NaCl}$ broth;

Table 1. Percentage inactivation of staphylococcal phages after 24 hr. incubation in 0.5 or $10 \%$ NaCl Trypticase soy broth at $30^{\circ}$

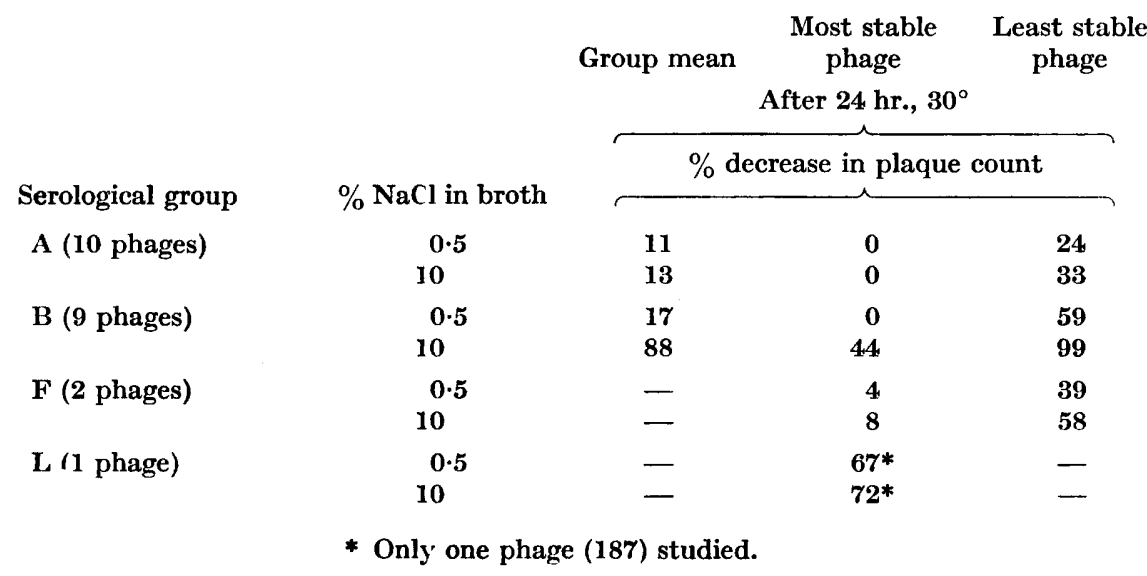


$24 \mathrm{hr}$. incubation in the presence of either $0.5 \%$ or $10 \% \mathrm{NaCl}$, a continuous decline in the quantity of active phage occurred throughout this period. Some typical results of plaque counts made during the first half of the period are given in Table 2 . In the case of phage 29 , for example, diminution in number of plaque-forming units after incubation in $10 \% \mathrm{NaCl}$ broth for $4 \mathrm{hr}$. was $24 \%$, after $12 \mathrm{hr}$. it was $70 \%$ and over $90 \%$ inactivated after $24 \mathrm{hr}$.

Table 2. Plaque counts of typical staphylococcal serological group $A$ phages (42B and 81) and group $B$ phages (29 and 70) after initial dilution and incubation at $30^{\circ}$ in $0.5 \%$ or $10 \% \mathrm{NaCl}$ Trypticase soy broth

\begin{tabular}{|c|c|c|c|c|c|c|c|c|}
\hline & \multicolumn{8}{|c|}{ Staphylococcal phages } \\
\hline & \multicolumn{2}{|c|}{ Phage 42 B } & \multicolumn{2}{|c|}{ Phage 81} & \multicolumn{2}{|c|}{ Phage 29} & \multicolumn{2}{|c|}{ Phage 80} \\
\hline & $\begin{array}{l}0.5 \% \\
\mathrm{NaCl} \\
\text { broth }\end{array}$ & $\begin{array}{l}10 \% \\
\mathrm{NaCl} \\
\text { broth }\end{array}$ & $\begin{array}{l}0.5 \% \\
\text { NaCl } \\
\text { broth }\end{array}$ & $\begin{array}{l}10 \% \\
\text { NaCl } \\
\text { broth }\end{array}$ & $\begin{array}{l}0.5 \% \\
\mathrm{NaCl} \\
\text { broth }\end{array}$ & $\begin{array}{l}10 \% \\
\mathrm{NaCl} \\
\text { broth }\end{array}$ & $\begin{array}{c}0.5 \% \\
\text { NaCl } \\
\text { broth }\end{array}$ & $\begin{array}{l}10 \% \\
\mathrm{NaCl} \\
\text { broth }\end{array}$ \\
\hline Time & \multicolumn{8}{|c|}{ Number of plaque-forming units } \\
\hline 0 & 250 & 247 & 137 & 137 & 188 & 178 & 203 & 179 \\
\hline 4 & 247 & 260 & 128 & 141 & 171 & 135 & 142 & 43 \\
\hline $10-12^{*}$ & 217 & 223 & 120 & 112 & 168 & 53 & 103 & 16 \\
\hline
\end{tabular}

* All $12 \mathrm{hr}$. counts except those of phage 81 which were made after $10 \mathrm{hr}$.

\section{DISCUSSION}

In addition to distinctive antigenicity, serological groups of staphylococcal phages are characterized by other properties including host range, plaque size, ability to form lysogenic systems and stability (Rippon, 1956). Rountree (1949) pointed out the relative instability of serological group B phages, particularly their marked sensitivity to heat and storage at $4^{\circ}$, as compared with that of the group $\mathbf{A}$ and $\mathbf{F}$ phages. In the first serological investigation of staphylococcal phages Burnet \& Lush (1935) observed that these phages could be divided into two categories, citrate-sensitive and citrate-insensitive. Rountree (1951) reported that most staphylococcal phages, when in the free state, were inactivated to some degree by $1 \%(\mathrm{w} / \mathrm{v}) \mathrm{Na}$ citrate and those most completely inactivated belonged to serological group B. In the same study, which was concerned chiefly with the effect of electrolytes on adsorption, evidence was presented that each phage had a characteristic calcium requirement. In all but two of the phages examined $\mathrm{Na}$ citrate inhibited phage adsorption and this effect was attributed to the action of the citrate radical which, it was suggested, bound the calcium on the surface of the phage and thus blocked the adsorption site. The absolute calcium requirement for propagation of serological group B phages was reported by Blair \& Williams (1961); phage 47C (group A) and phage 187 (group L) were the only other staphylococcal phages in this category.

In the present work the staphylococcal phages which were least stable when incubated without staphylococci in $10 \% \mathrm{NaCl}$ Trypticase soy broth were also those of serological group $\mathrm{B}$. The marked diminution in activity of these phages might be due to the effect of the $\mathrm{NaCl}$ on free phage before contact with the staphylococci 
or to the failure of adsorption because of the $\mathrm{NaCl}$ introduced with phage to the phage + bacteria mixture. If inhibition of adsorption as proposed by the latter explanation were solely responsible, equal diminutions in plaque counts should occur in the initial (0) sample and the $24 \mathrm{hr}$. sample which were both taken from $10 \% \mathrm{NaCl}$ broth. Mixing of $0.1 \mathrm{ml}$. of this broth with an equal amount of the broth culture of the propagating strain of staphylococcus, followed by immediate addition of $3 \mathrm{ml}$. soft agar, quickly diluted the concentration of $\mathrm{NaCl}$ to about $0 \cdot 8 \%$. The quantity of $\mathrm{NaCl}$ was further decreased on plating the soft agar. Rountree (1951) found that with the citrate-sensitive phages adsorption in $\mathrm{NaCl}$ was variable and, when it occurred, recovery of active phage from the bacteria infected in $\mathrm{NaCl}$ was less than from bacteria infected in $\mathrm{CaCl}_{2}$. These conclusions were based on experiments in which phages and bacteria were held $20 \mathrm{~min}$. in aqueous solutions of $\mathrm{NaCl}$ at lower concentrations than those in the phage + bacteria mixtures tested here. In our experience the most unstable phages of group B lyse susceptible staphylococci when $1 \% \mathrm{NaCl}$ Trypticase soy agar is used in the routine typing procedure.

If inactivation of free phage occurs in the $\mathrm{NaCl}$ broth before mixing with the staphylococci, one would expect a continuing decrease in the number of plaqueforming units with increase in time. This was observed to occur. In the case of the group B phages there was an immediate decrease, followed by progressive decrease in plaque count until, at the end of $24 \mathrm{hr} ., 12 \%$ or less of the original activity remained. Group A phages showed little, if any decrease in activity on initial contact with $10 \% \mathrm{NaCl}$ broth; when the activity was decreased after $24 \mathrm{hr}$. plaque counts made at 4-8 hr. intervals became successively lower. The inactivation of staphylococcal phages observed here appears to be an effect of $\mathrm{NaCl}$ on free phage.

The NaCl instability of serological group B staphylococcal phages observed in this work parallels their requirement for calcium. Two phages other than those of serological group $\mathrm{B}$, which have an absolute calcium requirement are $47 \mathrm{C}$ (group A) and 187 (group L) (Blair \& Williams, 1961). Phage 47C proved to be the most $\mathrm{NaCl}$ sensitive of the group A phages tested, but it was much more $\mathrm{NaCl}$ stable than any group $B$ phage. The salt tolerance of phage 187 and of the exceptional group $B$ phage 83 was intermediate between that of the average group $\mathbf{A}$ and group B phages, but they were almost as unstable in $0.5 \% \mathrm{NaCl}$ broth as in $10 \%$ $\mathrm{NaCl}$ broth. In general, inactivation in the higher concentration of $\mathrm{NaCl}$ was independent of stability in regular broth. Most phages retained their activity in $0.5 \% \mathrm{NaCl}$ broth, although there were individual differences within each group. No phage was more stable in $10 \%$ than in $0.5 \% \mathrm{NaCl}$ broth. $\mathrm{NaCl}$ tolerance appears to be a characteristic of certain staphylococcal phages, particularly those of serological group A, and this property may be useful in presumptive identification of serological group or in other classification schemes.

This work was supported by a grant from the National Institutes of Allergy and Infectious Diseases, United States Public Health Service. 


\section{REFERENCES}

Adams, M. H. (1949). The stability of bacterial viruses in solution of salts. J. gen. Physiol. 32, 579 .

Blair, J. E. \& Williams, R. E. O. (1961). Phage typing of staphylococci. Bull. Wld Hlth Org. 24, 771 .

Bronfenbrenner, J. (1925). Effect of electrolytes on the rate of inactivation of bacteriophage during precipitation. Proc. Soc. exp. Biol., N.Y. 23, 187.

Burnet, F. M. \& Lush, D. (1935). The staphylococcal bacteriophages. J. Path. Bact. 40, 455.

RIPPon, J. E. (1956). The classification of bacteriophages lysing staphylococci. J. Hyg., Camb. 54, 213.

Rountree, P. M. (1949). The serological differentiation of staphylococcal bacteriophages. J. gen. Microbiol. 3, 164.

Rountree, P. M. (1951). The role of certain electrolytes in the adsorption of staphylococcal bacteriophages. J. gen. Microbiol. 5, 673. 